\title{
Organ Measurement Domain
}

National Cancer Institute

\section{Source}

National Cancer Institute. Organ Measurement Domain. NCI Thesaurus. Code C49605.

A subject domain utilized for the submission of information encompassing and representing data, vocabulary or records related to organ measurement. 